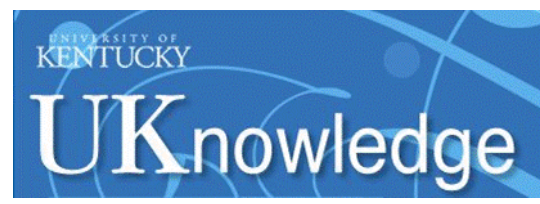

University of Kentucky

UKnowledge

$1-8-2021$

\title{
Two Separate Worlds, One Shared Goal: An Exploration of Special Collections Catalogers' Reporting Lines and Institutional Organization
}

\author{
Colleen W. Barrett \\ University of Kentucky, colleen.barrett@uky.edu \\ Whitney A. Buccicone \\ University of Virginia,wb8hb@virginia.edu \\ Joseph J. Shankweiler \\ Western Kentucky University, josephj.shankweiler@wku.edu
}

Follow this and additional works at: https://uknowledge.uky.edu/libraries_facpub

Part of the Library and Information Science Commons

Click here to let us know how access to this document benefits you.

\section{Repository Citation}

Barrett, Colleen W.; Buccicone, Whitney A.; and Shankweiler, Joseph J., "Two Separate Worlds, One Shared Goal: An Exploration of Special Collections Catalogers' Reporting Lines and Institutional Organization" (2021). Library Faculty and Staff Publications. 324.

https://uknowledge.uky.edu/libraries_facpub/324

This Book Chapter is brought to you for free and open access by the University of Kentucky Libraries at UKnowledge. It has been accepted for inclusion in Library Faculty and Staff Publications by an authorized administrator of UKnowledge. For more information, please contact UKnowledge@lsv.uky.edu. 


\section{Two Separate Worlds, One Shared Goal: An Exploration of Special Collections Catalogers' Reporting Lines and Institutional Organization}

Digital Object Identifier (DOI)

https://doi.org/10.1108/S0732-067120210000042009

Notes/Citation Information

Published in Technical Services in the 21st Century (Advances in Library Administration and Organization, v. 42). Samantha Schmehl Hines, (Ed.). p. 103-118.

Copyright @ 2021 Emerald Publishing Limited

This author accepted manuscript is deposited under a Creative Commons Attribution Non-commercial 4.0 International (CC BY-NC) licence. This means that anyone may distribute, adapt, and build upon the work for non-commercial purposes, subject to full attribution. If you wish to use this manuscript for commercial purposes, please contact permissions@emerald.com. 
Two Separate Worlds, One Shared Goal:

An Exploration of Special Collections Catalogers' Reporting Lines \& Institutional Organization

Colleen W. Barrett ${ }^{1}$, Whitney A. Buccicone ${ }^{2}$, and Joseph J. Shankweiler ${ }^{3}$

${ }^{1}$ Rare Books Librarian, University of Kentucky

${ }^{2}$ Head of Technical Services for Special Collections, University of Virginia

${ }^{3}$ Special Collections Catalog Librarian, Western Kentucky University 


\begin{abstract}
Cataloging has long been considered a fundamental component of special collections work. Beyond the ability to constantly adapt to new technologies and content standards, special collections catalogers also deal with special collections specific issues, from fragile or poorly preserved materials to the need to learn item specific terminology, like binding descriptions, to larger security concerns. By existing within the two worlds of both special collections and technical services librarianship, there is not always a clear answer to where and whom a position should report. The institutional role and best reporting structure of the special collections cataloger has yet to be well defined, categorized, or understood.

This chapter seeks to better understand and quantify some of the challenges current special collections catalogers face through conducting and analyzing the authors' recent survey of special collections catalogers primarily working in American cultural heritage institutions. While these findings are neither simple nor straightforward, it is possible to suggest some preliminary solutions. Overarching trends and challenges included communication between departments, security of valuable materials versus workspace locations, and priority setting.
\end{abstract}




\section{Introduction \& Background}

Cataloging has long been considered a fundamental component of special collections work --so much so that an entire series of National Endowment for the Humanities (NEH) grants was created to eliminate significant technical services backlogs of prior generations. Beyond the ability to constantly adapt to new technologies and content standards, special collections catalogers are also tasked with handling additional issues that are more pronounced in a special collections environment, including handling fragile or poorly preserved materials; the need to learn item specific terminology, like binding descriptions; and larger security concerns for materials. This extra layer often requires specialized knowledge that comes from both training and years of experience, but must also be combined with a deep understanding of the discovery systems used by institutions to facilitate collection access. By existing within the two worlds of both special collections and technical services librarianship, there is not always a clear answer to where and to whom a special collections cataloging position should report.

This chapter aims to better understand the current state of the field through an analysis of the authors' recent survey of special collections catalogers advertised mainly to those working in American cultural heritage institutions, along with some initial best practices for future managers regardless of departmental affiliation. Our hope is that this information will allow future researchers to further investigate the best ways to manage special collections catalogers regardless of their departmental affiliation.

\section{Literature Review}

A survey of scholarship shows that, while there is a significant amount of material written on technical services library management, there is surprisingly little discussion of the intersection between special collections and technical services departments. Specifically, there is not much exploration of how these departments work together in terms of reporting structures or open lines of communication for creating and maintaining bibliographical access to special collections materials. However, in the early 2000's, some librarians began to acknowledge and discuss the need for collaboration between cataloger and curator in order to streamline the cataloging process and reduce backlogs.

Bradshaw and Wagner (2000), in their article, "A common ground: Communication and alliance between cataloger and curator for improved access to rare books and special collections," push for a less siloed approach to cataloging rare materials, suggesting that "rare book catalogers and special collections curators can benefit greatly from cooperating on matters concerning cataloging policy and practice" (p.525). Specifically, Bradshaw and Wagner argue that catalogers should be aware and informed of collection strengths and the overall mission of the 
library in order to better prioritize their efforts. Additionally, the cataloger should be aware of the backlog's size and subject matter as well as the curator's priorities in order to best determine workflow and how to best manage the workload (Bradshaw and Wagner, 2000). Bradshaw and Wagner stress the necessity of a collaborative cataloging approach in order to speed up the process of shrinking the cataloging backlog, as they conclude "Based on an effective collaboration between cataloger and curator, customized cataloging can provide maximum access to special collections materials, to the benefit of all” (2000, p.533).

Similarly, in her article "Opening up special collections to the public: A partnership between cataloging and the special and area studies collections department at the University of Florida" Tatiana Barr (2004) acknowledges the need for overlap and flexibility between technical services and special collections departments, "Cataloging has worked on developing a realistic, flexible, and creative approach that includes working closely with curators, negotiating priorities, flexible staff assignments, exploiting cataloging options, special projects, applying for grants, developing a dynamic cataloging inventory, and other methods" (p.31). Most crucial to Barr's assessment is the push for close working relationships between curators and catalogers and an overall emphasis on flexibility. Barr stresses communication and collaboration between special collections and technical services such as allowing curators to create provisional records or collection level records for new acquisitions until more detailed records can be created.

Beth M. Russell (2004), in her article "Special collections cataloging at a crossroads: A survey of ARL libraries," details a survey administered to 114 participants through the Association or Research Libraries (ARL). Russell's study primarily seeks to investigate patterns and trends in departmental organization and reporting structures, in order to address the growing concern of cataloging backlogs and the resulting lack of access to special collections materials (2004). Similar to Barr and Bradshaw and Wagner, Russell notes the increased awareness in the early 2000's of growing backlogs in special collections libraries. She observes, "If managers and administrators of college and university libraries were ever content with large backlogs of unprocessed special collections, that time is past" (Russell, 2004, p.294). Russell (2004) specifically "examines the organizational structure of special collections cataloging, as well as the number and type of staff devoted to the endeavor," (p. 294) and concludes that while there is evidence of catalogers' commitment to creating access to special collections materials, there did not seem to be any "clearly dominant trends in organization, staffing, or workflow" (p.294).

Most recently, Turner and Shuster (2019) in their article "Carts in the hallway: Cataloging and special collections - A partnership for Success," use their institution as a case study to demonstrate how altering workflow and opening channels of communication between special collections and technical services has proven beneficial to overall productivity and "foster[ed] cooperative decision making in order to increase understanding of project priorities and allow 
for more efficient cataloging" (p.142). One primary concern Turner and Schuster address is the reporting structures for special collections catalogers and the physical location of collections versus where the physical cataloging is actually performed. Echoing previous assertions they note that, "even when an institution has catalogers who focus on special collections material, they are often located within technical services or a centralized cataloging department, not special collections" (Turner \& Schuster, 2019, p.143). Another major concern is that technical services units rarely have enough catalogers available and special collections often do not have a person dedicated solely to cataloging (Turner \& Schuster, 2019). While most academic discussion on the subject has generally been more descriptive in nature, Turner and Schuster prescriptively model the type of collaboration that can take place between the two departments to improve overall communication and efficiency. Their solution serves as a practical application of what librarians have been saying for the last 20 years, that "cataloging and special collections departments collaborate closely and build their lines of communication, so that they can communicate effectively to make items accessible" (Turner \& Schuster, 2019, p.144).

While there has not been much sustained scholarship dedicated to departmental organization and reporting structures for catalogers of special collections materials, it is clear that librarians are in agreement on the need for open lines of communication and collaboration between technical services and special collections in order to better achieve and maintain bibliographic control and improve access to special collections materials. This study hopes to further contribute to this ongoing conversation by exploring the ways in which catalogers are currently navigating the two worlds and working towards a common goal of better bibliographic access regardless of material type.

\section{Methodology}

\section{Survey Design}

The questions used in this survey were created by expanding and rewording those originally conceived and distributed by Buccione in a casual format through SurveyMonkey in May and June of 2018. The authors sought to broaden the survey by incorporating new topics and challenges mentioned in casual conversations at recent conferences. The final questions selected are attached as Appendix I.

The survey design thought process was focused on simplicity, flexibility, and approachability in an attempt to get responses from as many different types of special collections catalogers as possible. None of the questions were required for survey completion so that respondents could spend as much or little time on the survey as they wanted; the authors decided that it was 
more important to get a wider sense of the field than only a few specific and detailed snapshots. Following a submission of the survey questions to the University of Kentucky's Office of Research Integrity, IRB review was deemed unnecessary as the authors were asking about job descriptions and not about human subjects.

Considering the lack of research about this subject as discussed above, they opted for several open-ended questions that were not required for survey completion in the hopes that respondents would be able to freely share their experiences without being forced to choose only one answer over another. Some of these answers were later classified into broad categories to help better generalize responses.

\section{Survey Promotion and Timeline}

Once the survey design was complete, the authors sought responses through multiple cataloging listservs and social media forums both within official cataloging organizations and more casual groupings in the hope of reaching as many special collections catalogers as possible. Shankweiler posted emails to the listservs for the following: Descriptive Cataloging of Rare Materials (DCRM-L); Association of Library Collections and Technical Services (ALCTS); rare book focused EXLIBRIS; and Resource Description and Access (RDA-L). On social media, Buccione created posts in the Facebook group Troublesome Catalogers and Magical Metadata Fairies, a popular place for cataloging and metadata, as well as through the authors' personal Twitter accounts. They began promoting on 4 September 2019 with reminders sent to the same listservs on 20 September 2019 and ended the survey on 2 October 2019.

\section{Survey Results}

The original results consisted of 271 responses recorded through Qualtrics to ensure better privacy, but for the purpose of this analysis we omitted 3 survey preview responses, 12 completely blank responses, and 3 responses that only listed an institution type (two were museum and one was a historical society), for a total of 253 survey responses. Not all respondents replied to every question.

\section{Demographics}

Perhaps unsurprisingly, 174 of the respondents described their place of employment as an academic institution, with the next highest number at public (35), followed by other (26), museum (9), and historical society (9). A majority of special collections catalogers are in permanent full-time positions (219), followed by a tie between permanent part-time (12) and temporary full-time positions (12) with only a few that are grant-funded full-time (5), 
temporary part-time (3), or grant-funded part-time (2). Most of the surveyed special collections catalogers were classified as professional staff (102), followed by non-tenured librarian (61), tenured librarian (42), paraprofessional staff (29), other (18), and volunteer (1). Responses to the other category for classification included Academic, Non-Faculty, with indefinite appointment; Archivist; Contractor; Faculty (non-tenured); I'm a GS-13 on the federal schedule; Lecturer (Clinical and Instructional Librarian); Librarian; Library Professor, faculty but tenure is not presently extended to us; My institution doesn't classify positions in any of these terms, but my position is exempt \& salaried, "BA required, MLS preferred"; Professional Project Hire; Professional staff with continuous appointment (similar to tenure but not classified the same at our Uni); Recurring limited term (half time, no benefits); Tenure-track Faculty Librarian; tenuretrack librarian; and we do not have tenure here.

Two respondents that work full-time did not record how many hours they spend cataloging special collections materials, but of the 251 that did, a majority spent $0-5$ hours a week cataloging them (66), followed by 31-40 (50), 11-20 (49), 6-10 (46), and 21-30 (40) (fig. 1).

[Figure 1 here in text]

\section{Reporting Structures and Materials Location}

Of the 249 respondents that answered the question, 134 were hired by departments or individuals that were different from to whom they reported while 115 were hired by the department to which they report. Of the 217 respondents that replied, a majority of workloads were determined by a combination of both technical services and special collections (78), followed by special collections (57), cataloging/technical services (45), and other (37), several of which indicated that priorities were set by the cataloger themself.

Of the 215 respondents that answered the question, 126 (58.6\%) had their physical collections housed in the area in which they worked while 89 (41.4\%) did not. For those that did not have their physical collections housed where they work, 42 reported that it did impact their work, 16 reported that it sometimes impacted their work, and 25 reported that it did not impact their work for a total of 83 responses to this open-ended, follow-up question.

\section{Satisfaction with Reporting Structure}

Of the 208 respondents that answered the question, 145 were satisfied with their current communication structure, while 38 were possibly satisfied and 38 were not. When an issue arose between the special collections and technical services departments, 170 respondents 
reported that 131 were able to interact directly with other departments, 30 used a combination of direct and intermediary contact, and 9 only used contact through an intermediary. When asked an open ended question on the strengths and challenges of the current institution's approach, 188 respondents provided commentary on the strengths and 190 did so for challenges.

\section{Discussion}

Multiple themes emerged that crossed institution type as well as rank and seniority of the respondent in our open-ended questions that merit a closer examination here: advantages and disadvantages to their current reporting structure; the impact of the separation of materials from a cataloger's physical location; and communication structure.

\section{Reporting Structure}

As the qualitative data shows above, the reporting structure for a special collections cataloger did not clearly fall into one obvious departmental designation, suggesting that different approaches are working for different institutions. Both possibilities can create complications. When reporting to central technical services, the special collections part of the cataloger's job can be ignored or misunderstood by their co-workers, or, worse, their supervisors. When reporting to special collections, catalogers can become isolated from their fellow catalogers. Through the question "What are the strengths of your institution's approach?" respondents offered multiple thoughtful perspectives in favor of both reporting to a technical services department and a special collections department.

Those who report to a technical services department noted some of the strengths for their institution's approach:

- Because we have a relatively small cataloging staff for an institution of our size, we can take advantage of language and format expertise of people who aren't designated as special collections catalogers. Because we are in the Data \& Technology (i.e. IT) division, we have somewhat better access to tech help and collaboration.

- Centralized cataloging unit means more consistency in policy and training. Catalogers can be deployed to different special collections based on need and expertise.

- Having all of the catalogers within my institution report directly to one department (Tech Services), rather than having them assigned to individual branches ensures the quality of the cataloging and the records. 
- Having Special Collections treated as a unit of Metadata Services proper allows for cross collaboration across cataloging centers and helps ensure that both Special Collections and General Collections records play nicely together in shared catalog

- I am in the same department with the non-special collections catalogers and have a good working relationship with them for feedback and advice.

- I catalog and deal with catalog and cataloging issues, rather than being diverted into other kinds of SC tasks and activities. I don't have to convince my superiors about cataloging and systems issues and best practices.

- I have appreciated the opportunities that I have (or take) to communicate informally with Rare Books staff. My location in Cataloging and Metadata reflects the fact that I am responsible for more than just special collections materials; it also gives me an opportunity to stay up-to-date with the many recent developments in the field of cataloguing, which people in special collections units who perform cataloguing on a part-time basis often miss.

- Reporting to the cataloging department makes more sense because of our shared expertise in library data/standards; important to communicate effectively $\mathrm{w} /$ curators but not give them too much control over special collections catalogers' work.

Those who report to a special collections department noted some of the strengths for their institution's approach:

- Each department can decide what it needs cataloged first, depending on patron usage, rarity/fragility, etc.

- Each library is responsible for their own cataloging - allows catalogers to be specialists, not generalists.

- Having rare books cataloging in Special Collections means we are tied in with other special materials cataloging (Manuscripts, Digital objects, etc.) and can take a unified approach to serving Special Collections patrons' needs. We are also more aware of what is happening with public services and their needs.

- It allows me to concentrate my efforts on special collections; I can participate in initiatives or activities outside of Special Collections, if I so choose, on a case by case basis.

- It gives them another person to work on and be knowledgeable about spec coll materials besides the two catalogers who do that full time. At times I was the only cataloger down here working on this.

- More security for the materials; more opportunity/easier communication with curators; participating in public service.

- Physical proximity to and organizational relationships with the curatorial staff and special collections research and instruction staff ensures that cataloging has close 
communication with these units to address remediation needs, answer questions about the functioning of the catalog, and get additional contextual information on materials to be cataloged as necessary. This also allows catalogers to know more about the patron experience with records to inform cataloging. Cataloging is within the same department as archival processing because of the strong connections between our work, allowing us to more easily discuss issues of description that cross bibliographic/archival divides. Housing special collections cataloging within special collections prioritizes the particular needs of the materials, as the general technical services department does not understand the additional descriptive needs of special collections materials nor the additional skills that are required of catalogers.

Of course, either of these approaches can also cause difficulty with the other department without proper communication structures in place. One respondent that reports through technical services noted "I do not work in the building where my "home" unit is, so I am left out of a lot of things there. Also, the person who is most knowledgeable about my progress on projects is not the person to whom I report and, thus, not the person who evaluates my performance. The person who does evaluat[e] my performance is less knowledgeable about my work so I spend a lot of time keeping them informed." while another that reported through special collections remarked, "We are less connected to the Cataloging Department, and not always on the same page with them on issues related to the online catalog as a whole."

\section{Priority Setting}

Another aspect of a given reporting structure is priority setting. Many catalogers exist in a world of production, where quantity is valued over quality, and the more detail and researchoriented subsection of special collections cataloging has difficulty maintaining the same pace of other subsections. If central technical services only focuses on numbers, then the rare and valuable materials that take longer to catalog will not make the priority list for central technical services even though a special collections department will want them to be accessible and secure. Some examples of successful collaborative approaches described within the survey included:

- Curatorial staff set priorities but technical services can weigh staff abilities and time to organize work flows.

- Each special collection has specific priorities for the rare books cataloger and communicates those well. They are accepting that the position catalogs for all of the various special collections and that things will not always be completed immediately. 


\section{Catalogers and Materials Location}

As stated above, a slight majority of those doing special collections cataloging work have collections housed alongside their workspace, which holds true regardless of the amount of hours spent cataloging every week (fig. 2).

[Figure 2 here in text]

When those who have collections housed separately from their workspaces were asked about the impact of the practice, slightly more than half stated that there was an impact and $69.9 \%$ mentioned that there was at least sometimes an impact, though no attempt was made to establish if said impact was positive, negative, or neutral. One stated concern was maintaining the safety of the materials, whether from theft, poor environmental conditions, or other conservation issues such as mold.

\section{Communication Structure Satisfaction}

As previously discussed in the field's literature and indicated by survey responses, communication is paramount. Thankfully survey results indicate that communication lines are mostly positive for modern special collections catalogers, with many catalogers feeling free to contact colleagues in other departments with questions or to ask for clarification.

Despite these positive structures, one must remain vigilant against misunderstanding across divisions, whether it be from a special collections colleague not understanding bibliographic standards, or a supervisor in cataloging feeling that special collections materials are not, indeed, special. Occupying this liminal space can foster a feeling of isolation from other catalogers and metadata experts, as described by respondents below:

- Being physically located away from the main cataloging unit can make us feel isolated.

- Direct access to the director [of Special Collections], who can see the big picture when it comes to special collections and archives various functions, and who in turn has access to and influence with the Dean of the libraries.

- Not always easy to communicate with Supervisor [of Central Technical Services].

- I'm not $100 \%$ sure that I'm providing the service that the rare books curators want. I'm not sure how much the rare books curators know/care about the library catalog and how it works.

- We have less communication with Special Collections, which creates a lack of understanding about our work.

- Rare book catalogers work in the main library, but most cataloging staff work off-site, making it difficult to meet. 
- Miscommunication sometimes around not necessarily knowing who all needs to be included in email communication and in person conversations not always being followed up on due to lack of thorough documentation of these conversations.

- Getting approval for changes can take months because of layers of input.

- I report/communicate with people who don't know cataloging.

- Since I get work from many different people, they are often unaware of how many items other curators have recently given me and therefore don't understand why I can't catalog their items immediately.

- There is sometimes a disconnect between supervisors.

- The Special Collections folks don't quite understand how the catalog record works, lots of explaining and re-explaining. Also, the Special Collections folks want all sorts of exceptions that we have to work around to get them what they want within the cataloging rules. They are very set in their expectations of how the information should be in the public discovery system. Resistant to change, like they usually describe catalogers!!

- My supervisor is not interested or really experienced in special collections, and I think the point I have more training than he does on special collections cataloging. I think it would make more sense to have a full-time cataloger in the rare book department, and to have that person report to rare book experts who have an understanding of what catalog records should look like.

- Other library catalogers (and Resource Services department in general) has little to no understanding of the particular needs and priorities of special collections cataloging.

\section{Suggestions for Improvements}

\section{The ideal reporting department}

As outlined above, there are both benefits and challenges to reporting within technical services or special collections as a special collections cataloger. Regardless of the home department, there must always be considerations of potential communication issues, understanding of the work being done, and care taken in regards to the location and/or transportation of materials. Rather than prioritizing the desires of one department over another, managers would do well to focus on the safety of the materials and their cataloger's access to them. In doing so, the departmental designation of a manager becomes almost irrelevant. Catalogers who are responsible for cataloging special collections materials can be managed by anyone who is willing to understand that this material can be challenging and requires special handling. Like all technical services work, in the end, this is about access and doing what is best for the users. 


\section{Priority setting}

Beyond making regular communication a natural part of the workspace, regular meetings and shared documentation can help create a space where conflict over priorities is avoided. Cataloging priorities must be documented and communicated to all affected parties, especially if multiple curators share a small cataloging staff. Meetings to write a list of cataloging priorities that allows for shared time should occur periodically, ideally at least once a semester or quarter. When completed, these priorities should be e-mailed out to all involved to ensure the communication loop is closed. In addition, any workflow for "emergency" cataloging, meaning last minute cataloging needs that usually come from donor visits, exhibitions, or last minute class requests, should be put in place and agreed upon by all involved. Clear expectations should also be documented: what turnarounds are expected; who is responsible for the material after cataloging; etc.

\section{Regular meetings, documentation, and transparent workflows}

In the theme of communication, we repeatedly saw that issues arose when there were no regular meetings between special collections staff and the cataloger responsible for their materials. Regularly scheduled meetings between these groups should be scheduled, whether that is once or twice a month. From these meetings, decisions regarding workflows, policies, and procedures should be documented and these documents should be easily accessible by all parties in a virtual shared space, whether that be Google Docs, DropBox, or another option, not as a paper copy in only one department or on the local drive of the cataloger's desktop. Any and all additional documentation related to special collections cataloging should also be in a virtual shared space.

The cataloging workflows documentation should be detailed and easy-to-read so anyone, including supervisors from other departments, can read them clearly and without needing to know abbreviations, lingo, etc. If a special collections cataloger is managed by someone who does not understand the specificities required for this type of cataloging, documentation may alleviate miscommunication about why this type of material needs more time and attention. This can also illuminate the process for everyone.

\section{Defined hierarchy and responsibilities}

Due to the liaison-like nature of the position, a special collections cataloger should have guidance and a designated contact in other departments should conflict arise. Casual interactions between departments is ideal, but having an official line of communication for formal situations may prevent unpleasant situations from occurring. This is something else to be documented and posted in a public place where both departments have access. 
Regular meetings should also be occuring at the department head and management level to ensure that managers responsible for the staff involved, whether that be curators, catalogers, or other invested parties, are still on the same page with priorities and workflows. If the cataloger reports through special collections, there should be regular meetings between their supervisor, who may or may not be trained in cataloging, and them. This will provide a more formal opportunity for periodic clarification of the more technical services based considerations in regards to special collections cataloging and will hopefully help prevent the special collections cataloger from needing to constantly explain their process to other parties.

\section{Keep the cataloger with the materials}

Since the materiality of special collections materials is an integral part of cataloging these resources, having catalogers work near their collections is an important consideration. When a cataloger is physically embedded at a desk in a central technical services, issues arise from having the material brought from special collections to the cataloger -- who will transport materials, how will they be tracked, etc. Further issues arise when food and drink are allowed at people's desks. Beyond the risk of spills onto rare materials, food and drink draw the attention of insects, mice, and other creatures that like to nibble leather and vellum bound volumes. If cataloging special collections materials is a significant part of a cataloger's job, it only makes sense for them to have a workspace near the materials instead of trying to find a safe, secure, and well-documented way to bring the materials to them.

\section{Suggestions for Future Research}

Beyond the data collected here, future research may seek to learn more about the educational background, training experiences, position longevity, time spent in the profession, and an exploration of other job tasks, such as reference and outreach, of special collections catalogers at all institution types. A similar study of archivists responsible for processing and metadata creation might also shed light on the state of the profession in a larger way, especially since not all archivists report to a special collections department and there may be similar departmental reporting opportunities and challenges.

Other research might focus on the management training practices for special collections catalogers and their career trajectory as a means to protect and grow this specialized sector of the profession. Though it would be harder to connect with them, an investigation of special collections catalogers' turnover focusing on the largest factor that motivated individuals in this group to either change institutions or, in some cases, professions, could be the start of a larger 
conversation on morale and retention in technical services, whether that is in special collections or outside of it.

Related to this, there is room for examination on the role of special collection catalogers and other technical services workers being involved with reference and outreach, something classically considered for only public services workers. It would be interesting to explore what the impact of having those who work with materials closely during the cataloging and processing workflows might be on the reference and outreach side of special collections work.

\section{Conclusion}

There is no such thing as a typical special collections cataloger. The state of the field seems to be in a much better state than anecdotally understood for both those cataloging special collections materials as a small part of their position responsibilities and those cataloging special collections material as a main job responsibility, though there is still much to be learned from future surveys and discussions. Our findings would seem to suggest that no matter where special collections catalogers report, they may encounter similar problems, though many of these problems can be prevented through intentional communication and collaborative priority setting as discussed above. 


\section{References}

Barr, T. G. (2004). Opening up special collections to the public: A partnership between cataloging and the special and area studies collections department at the University of Florida. Technical Services Quarterly, 21(4), 31-43. doi:10.1300/J124v21n04_03

Bradshaw, E. B., \& Wagner, S. C. (2000). A common ground: Communication and alliance between cataloger and curator for improved access to rare books and special collections.

College \& Research Libraries, 61, 525-534. doi:10.5860/crl.61.6.525

Lundy, W. M. (2007). Providing access to uncataloged special collections with in-process records. Cataloging \& Classification Quarterly, 45(1), 39-58. doi:10.1300/J104v45n01_04

Russell, B. M. (2004). Special collections cataloging at a crossroads: A survey of ARL libraries. The Journal of Academic Librarianship, 30(4), 294-303. doi:10.1016/j.acalib.2004.04.001

Turner, R.B. \& Schuster, D. (2019) Carts in the Hallway: Cataloging and Special Collections - A Partnership for Success. Technical Services Quarterly, 36:2, 142-154, DOI: 10.1080/07317131.2019.1584982 


\section{Appendix I: Survey Introduction and Questions}

For the purpose of this survey, we define "special collections materials" as any material that requires specialized housing or access and is of interest beyond the intellectual content contained within, and "cataloging" as the copy, enhancing, or creation of original records in OCLC and OCLC based library systems using standards such as MARC, DCRM, DCRMB, RDA, or AACR2.

This survey is in full compliance with IRB and no personal information will be used or shared with any other party. Answers to this survey will be used as a part of a book chapter in the forthcoming monograph, Technical Services in the 21st Century Library, edited by Christine Dulaney as part of the Advances in Library Administration and Organization series edited by Samantha Hines. The authors are Whitney Buccicone, Joseph Shankweiler, and Colleen Barrett.

If you have any questions or comments, please do not hesitate to email us.

1. What type of institution do you work at?
a. Academic
b. Public
c. Historical society
d. Museum
e. Other w/blank space

2. What is your position title?

3. What rank is this position classified as?
a. Tenured librarian
b. Non-tenured librarian
c. Professional staff
d. Paraprofessional staff
e. Intern
f. Volunteer
g. Other w/ blank space

4. What is the nature of this position's funding?
a. Permanent
b. Grant funded
c. Temporary

5. Are you full-time or part-time?
a. Full-time (30 or more hours)
b. Part-time ( 29 or under) 
6. How many hours per week do you spend cataloging special collections materials?
a. $0-5$
b. $6-10$
c. $11-20$
d. $21-30$
e. $31-40$

7. Which department do you report to?

8. Which department hired you?

9. Which department funds your professional development or provides training for you?

10. Who determines your workload priorities for cataloging?
a. Special Collections
b. Cataloging/Technical Services
c. Combination of both
d. Other w/ blank spot

11. With whom do you communicate about your workflow and progress? What communication methods do you use?

12. Are you satisfied with your current communication structure?

13. What are the strengths of your institution's approach?

14. What are the challenges of your institution's approach?

15. Are your physical collections housed in the area you work?
a. Yes
b. No

16. If the materials are housed separately, how do you access them for cataloging?

17. Does the separation of the materials from your work space impact your work? How?

18. Are there other challenges that you view as unique to your position?

19. When an issue arises, do you deal directly with special collections / technical services (depending on your home department) or do you communicate through an intermediary? [For example if you are in technical services and there's a problem can you speak to the curator, or, if you are in special collections and you need specific permissions or fields made visible in the catalog record, can you speak directly with technical services?] 


\section{Appendix II: Advertisement Emails \& Tweets}

2 September 2019 email

Hello!

We are e-mailing you today in hopes you will complete our survey https://uky.az1.qualtrics.com/jfe/form/SV_79QS69Sz56umpCd. We are studying special collections catalogers and how their reporting lines differ from a non-special collections cataloger. If you catalog special collections materials, such as rare books, archival collections, and more, we would greatly appreciate your input. Information gathered will be used in a book chapter to be published in Technical Services in the 21st Century (publishing date estimated 2020). All responses will be kept anonymous and only used for this book chapter.

Thank you in advance for your time and responses!

If you have any questions, please let us know.

Whitney Buccicone: wb8hb@virginia.edu

Joe Shankweiler: josephj.shankweiler@wku.edu

Colleen Barrett: Colleen.Barrett@uky.edu

20 September 2019 reminder email

If you haven't had a chance to participate in our survey, you have until October $1^{\text {st }}$. Thanks to everyone for your help!

Hello!

We are e-mailing you today in hopes you will complete our survey https://uky.az1.qualtrics.com/jfe/form/SV 790S69Sz56umpCd. We are studying special collections catalogers and how their reporting lines differ from a non-special collections cataloger. If you catalog special collections materials, such as rare books, archival collections, and more, we would greatly appreciate your input. Information gathered will be used in a book chapter to be published in Technical Services in the 21st Century (publishing date estimated 2020). All responses will be kept anonymous and only used for this book chapter.

Thank you in advance for your time and responses! 
If you have any questions, please let us know.

Whitney Buccicone: wb8hb@virginia.edu

Joe Shankweiler: josephj.shankweiler@wku.edu

Colleen Barrett: Colleen.Barrett@uky.edu 


\section{FIGURE 1: WEEKLY HOURS SPENT CATALOGING SPECIAL COLLECTIONS MATERIALS}

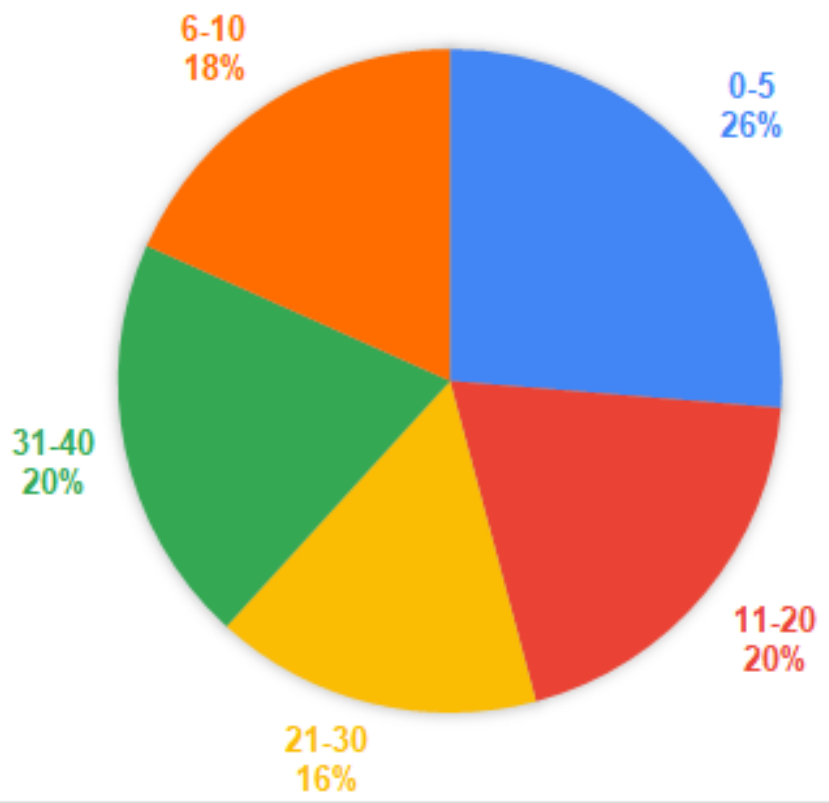

Figure 2: Cataloger's Workspace and Physical Materials Arrangement Broken Down by Hours Spent Cataloging Special Collections Materials Per Week

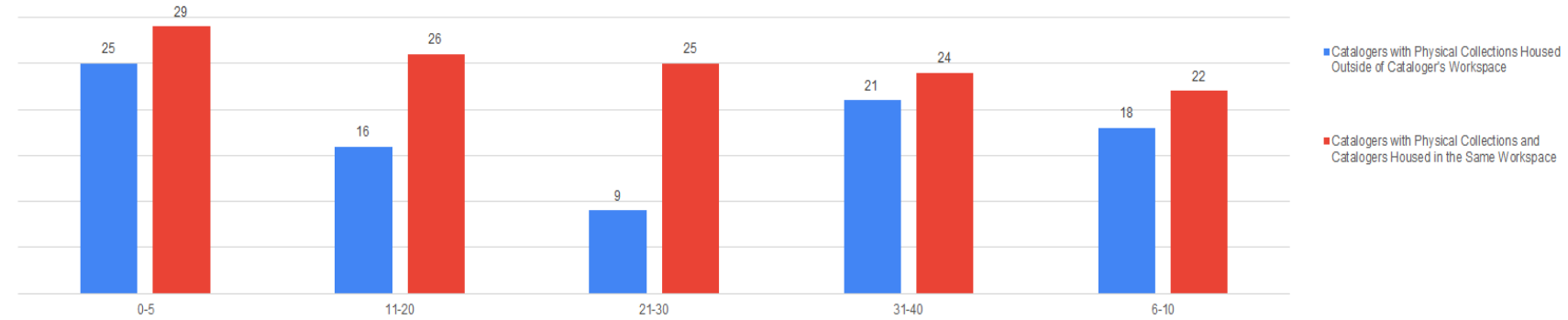

